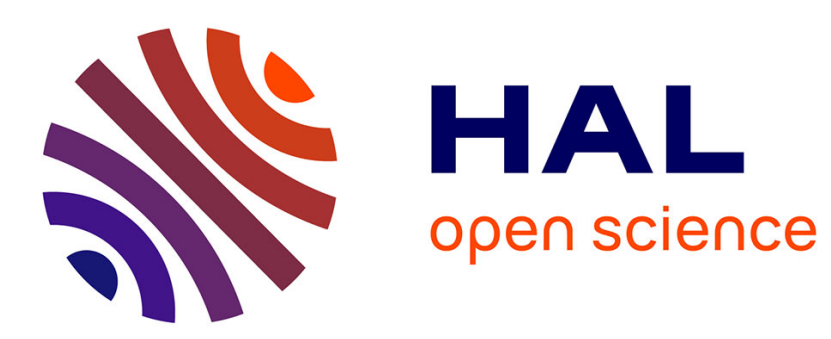

\title{
Bat flight height monitored from wind masts predicts mortality risk at wind farms
}

Charlotte Roemer, Thierry Disca, Aurélie Coulon, Yves Bas

\section{To cite this version:}

Charlotte Roemer, Thierry Disca, Aurélie Coulon, Yves Bas. Bat flight height monitored from wind masts predicts mortality risk at wind farms. Biological Conservation, 2017, 215, pp.116-122. 10.1016/j.biocon.2017.09.002 . hal-02563981

\section{HAL Id: hal-02563981 \\ https://hal.science/hal-02563981}

Submitted on 5 May 2020

HAL is a multi-disciplinary open access archive for the deposit and dissemination of scientific research documents, whether they are published or not. The documents may come from teaching and research institutions in France or abroad, or from public or private research centers.
L'archive ouverte pluridisciplinaire $\mathbf{H A L}$, est destinée au dépôt et à la diffusion de documents scientifiques de niveau recherche, publiés ou non, émanant des établissements d'enseignement et de recherche français ou étrangers, des laboratoires publics ou privés. 
C. Roemer ${ }^{1,2}$, T. Disca ${ }^{2}$, A. Coulon ${ }^{1,3} \&$ Y. Bas ${ }^{1}$

$4 \quad{ }^{1}$ UMR 7204 CESCO, Museum National d'Histoire Naturelle (MNHN), Paris, France

$5 \quad{ }^{2}$ Biotope, Mèze, France

$6{ }^{3}$ CEFE UMR 5175, CNRS - Université de Montpellier - Université Paul-Valéry Montpellier - EPHE,

7 Laboratoire Biogéographie et Ecologie des Vertébrés - 1919 route de Mende, 34293 Montpellier,

8 France

Corresponding author:

Charlotte Roemer

12 22 Boulevard Maréchal Foch, BP 58 - 34140 Mèze, France

$13+33(0) 467184620$

croemer@biotope.fr

Abstract

Bat fatalities by collision or barotrauma at wind farms currently raise high conservation concerns. In many countries, pre-installation acoustic surveys are mandatory in order to assess the impacts of wind farm projects. In this purpose, the use of wind masts to estimate bat activity and hence predict collision risk is highly recommended by conservation committees worldwide. Yet, the degree to which collisions may be predicted from acoustic monitoring at wind masts has been strongly debated.

To assess this relationship, microphone arrays were installed on 23 wind masts in order to record and locate bat activity on the vertical axis during 3,260 nights. For each species, we also calculated a collision susceptibility index, based on fatality data gathered in the literature and corrected for species abundance. We demonstrate that the collision susceptibility index is correlated with the percentage of bat passes at blade height. 
The acoustic recordings allowed us to establish a reference for the ratios of flight activity above heights of 20-45 m high for more than 16 European bat species. The correlation we demonstrate here between the percentage of bat passes at height - recorded from acoustic surveys on wind masts - and bat fatalities strongly supports that activity estimates from wind masts are appropriate for wind turbine impact assessments.

\section{Highlights}

- The most complete dataset of bat flight height distribution is presented

- A bat collision susceptibility index to wind turbine collisions was calculated

- The collision susceptibility index is correlated with time spent at blade height

- Results support the relevance of using wind masts for impact assessment studies

\section{Key words}

bat, wind turbine, carcass, impact assessment study, wind mast, actichiro

\section{Introduction}

Green energy development is today one of the top priorities of European governments. To answer this requirement, wind farm implantations have increased tremendously over the last years (Leung and Yang, 2012). Meanwhile, their impact has been proven lethal for numerous bird and bat species (Rydell et al., 2010a; Drewit and Langston, 2006; Frick et al., 2017; Hammerson et al., 2017). In Europe, cases of fatalities by collision or barotrauma around wind turbines (WT) have been reported in 27 bat species over the 51 extant European species for a total amount of circa 7,000 individuals and France alone has an impact on at least 17 species (Rodrigues et al., 2015). Since a very small proportion of wind farms were surveyed and for a limited period of time, this number is only the tip of the iceberg. Estimates show that in Germany alone, wind turbines may account for more than two 

million bats killed over the past 10 years, if mitigation measures were not practiced (Voigt et al., 2015)

All European bat species are under strict protection (Habitat Directive, Annex IV - Council Directive 92/43/EEC, 1992), hence the necessity to develop proper tools to assess as accurately as possible the impacts of human activities before their occurrence on bat populations. Today, European impact assessment studies monitor bat activity with methods ranging from evening transects with ultrasound detectors or autonomous overnight recordings from the ground to long-term recordings with microphones at height (Rodrigues et al., 2015).

To explain bat fatalities at WT and in the hope of predicting them, numerous hypotheses have emerged concerning the ultimate causes of collisions (Cryan and Barclay, 2009). The simplest explanation would be that mortality is directly linked to specific activity rates on site, independently from altitudinal distributions. However, uncommon species are sometimes more impacted than others (e.g. Georgiakakis et al., 2012). Some hypotheses suggest that species mostly impacted are annual migrants that might be seasonally manoeuvring at heights with collision risks, or that they are tree roosting species that might mistake wind towers for trees (Cryan and Barclay, 2009; Cryan et al, 2014; Jameson and Willis, 2014). Rydell et al. (2010b and 2016) doubt that migration is the only explanation for collisions because resident species are very often the most impacted species, and because insects resting on WT were identified in the stomach contents of bat carcasses found at wind farms. They conclude that there might not be a single explanation to the complex phenomenon of bat collisions at wind farms.

Before investigating complex hypotheses, it is important to focus on straightforward relationships. In all simplicity, bats spending most of their time foraging and commuting at similar heights as blade heights should be more susceptible to collisions. This assumption of coincidental collisions (Cryan and Barclay, 2009) has never been thoroughly investigated because of the lack of appropriate tools, i.e. tools that would not produce any attraction phenomenon. 
Yet, in order to estimate impacts before the setting up of wind farms, the more the setting resembles a WT, the easier it will be to estimate future impacts and draw conclusions. Hence it is not necessarily desirable to free the survey material from any effect on bat behaviour. Korner-Nievergelt et al. (2013) demonstrated that bat activity at WT nacelles is correlated with the number of carcasses found at their foot. But it has never been formally proven that this correlation is also valid for pre-construction acoustic surveys from wind masts, which are recommended for impact assessment studies (Rodrigues et al., 2015). An attempt by Hein et al. (2013) was not conclusive because of the variability in the methods of the studies that were available. Yet, this relationship most probably exists, notably because there is evidence that tall anthropogenic structures engender an attraction phenomenon toward tree roosting/migratory bats at the same time of the year where mortality peaks at WT are found (Jameson and Willis, 2014). Those bats are not the only species affected by WT collisions and others such as exclusive cave roosting species are also implicated although at much lower rates (e.g. Miniopterus schreibersii, Rodrigues et al., 2015). It might be that specific differences in flight behaviour play an important role in explaining differences in collision susceptibility among tree roosting/migratory species but more generally among all bats, and this concomitantly to an attraction phenomenon. Müller et al. (2013) showed that wind turbine fatality counts are numerous for most species flying more often around tree canopy than close to the ground. But a clear identification of the role played by bat flight height distribution in species susceptibilities to collisions, independently of species relative densities, is still missing. This distinction is for instance essential in order to rank species susceptibility. To perform this distinction between species behaviour and density, the latter must be corrected by using a reference scale for species activity levels (see Haquart, 2013).

Our study aims at testing the relevance of using activity data from wind masts in wind farm impact assessment studies. Our hypotheses are that (1) WT collision susceptibility is strongly linked to the preference of species flying at altitudes similar to those of WT blades, and that (2) this correlation can be established from observations at wind masts, as they act as a similar stimulus as WT toward bats. 


\section{Material and Methods}

\section{Acoustic recordings}

Recordings were conducted at 23 sites in France and Belgium (see Figure 1) between 2011 and 2016. Habitats consisted in pine, spruce and mixed forest clearings (11 sites), bocage (3 sites) wetlands (1 site) and cultivated fields (8 sites). Sites in Southern and Eastern France were either located in mountainous areas or in plains while the remaining sites were in plains only. Months between April and October cumulated the maximum number of sites surveyed per night (Figure 2). In total, bat activity was monitored on 3,260 nights $(\mu=142, \sigma=72$ nights per site). The recording period at each site did not exceed one year.

In order to establish a link between bat behaviour before the presence of WT and the collision risk after their activation, a proper manner to assess bat flight height distribution had to be chosen. Collins and Jones (2009) obtained differences between bat activity at ground level and at height by mounting one microphone at ground level and one at $30 \mathrm{~m}$ on a mast. With two unsynchronised microphones however, the most detectable species might be counted twice (i.e. at both microphones). Some species can indeed be acoustically detected at more than $90 \mathrm{~m}$ (Holderied and von Helversen, 2003; Barataud, 2015). Here, we performed a binary location of the bat position (i.e. near the nacelle height or near the ground), without any double count, while at the same time enabling a specific identification through the echolocation calls.

We installed microphones on lattice or monopole wind masts of 50-100 $\mathrm{m}$ high that all had aviation lighting at night. Arrays with two microphones were achieved with two SMX-US microphones plugged to an SM2BAT (all models, Wildlife Acoustics, Massachusetts, USA). Microphones were inserted into aluminium tubes, facing downward, in protection from weather alterations. The omnidirectionality of the setting was ensured by a custom-made round shaped 6 cm diameter aluminium reflector placed below the microphone with a $45^{\circ}$ angle. Microphones were respectively 
installed at heights ranging from 4 to $85 \mathrm{~m}$ (see Figure 3). Recorders were programmed to start each day 30 min before sunset and stop 30 min after sunrise. For study sites between 2013 and 2016 (13 sites), whole night recordings were performed. On study sites from before 2013 (10 sites), samplings were collected during 10 minutes every 20 minutes. Gain was set at $36 \mathrm{~dB}$, sampling rate at $192 \mathrm{kHz}$, trigger at $6 \mathrm{~dB}$ above background noise and trigger window at $2.5 \mathrm{sec}$. A $1 \mathrm{kHz}$ high pass filter was used. Files were compressed in WAC4 format and analysed in WAV format.

\section{Species identification and flight height classification}

Files were decompressed using the WAC2WAV (Wildlife Acoustics, Massachusetts, USA) software. When longer, files were automatically cut in 5 second bouts after each triggered recording to be used as a proxy for a bat pass, according to Barataud's method (2015). Species identifications were performed on SonoChiro (Biotope, France) (Newson et al. 2015). The verification of acoustic sequences was done on Syrinx (John Burt, USA) or BatSound (Pettersson Elektronik AB, Sweden) with spectrogram representations, allowing to measure acoustical parameters. Identification criteria are based on the association between acoustic call type, call shapes and measurable parameters (initial frequency, terminal frequency, signal length, maximum energy and its repartition ...), their rhythms (interval duration between calls) and the environment (distance to obstacles). With the knowledge accumulated today, this method born from Barataud's work (2015) allows the identification, in good recording conditions, of 29 species from the 33 extant in France and Belgium. Yet, sonar calls of certain species are sometimes very close, even identical in certain flight circumstances. Hence, they are assembled in species groups. In the present case, Myotis were grouped in two categories: Myotis myotis and M. blythii in a "large Myotis" group and all others in a "small Myotis" group, and all Plecotus individuals in the Plecotus sp. group. Within those two groups, species present flight heights comparable to the other species of their group (Rodrigues et al., 2015). It was however not acceptable to group unidentified species from Pipistrellus or Nyctalus/Eptesicus/Vespertilio genera, because they display very different flight heights within their group. These unidentified bat passes ( $2.95 \%$ of all bat passes) were not used for further analyses. 
In order to classify flight heights, SonoChiro was used to automatically determine the time at which each call starts on each microphone. Then, using the find.matches function of Hmisc package (Harrell, 2014) from R (R Core Team, 2014), we obtained the time differences of arrival for each call detected.

For each site, a height threshold was defined as the median height between the two microphones (see figure 3). This threshold corresponds for each site to the lowest height at which the planned WT blade would operate and therefore the altitude above which collisions can occur. This means that in forests also, the median height represents the height above which bats would be at collision risk. This threshold was used to assign bat calls to two classes: "at height" if the source of the signal is above the threshold and "at ground level" if it is below the threshold. If a bat call is detected by the highest or the lowest microphone only, the call is considered to be respectively located at height or at ground level. If several calls of the same bat pass give different location results (both at ground level and at height), location is determined by a majority vote among the calls (e.g. if 12 calls are at ground level and three calls are at height, the bat pass is assigned to "at ground level"). We then calculated a ratio of the time spent at height for each species. This method has also the advantage of freeing the comparison of several study sites from detectability bias linked to the type or the quality of the recording equipment. The count of the number of bat passes at height would be itself more prone to such bias.

\section{Calculation of collision susceptibility index}

Mortality data (total amount of bat carcasses found at WT) were transmitted by the agreement on the conservation of populations of European bats EUROBATS (2015 update). The identity of the sites surveyed and the months during which carcass searching was performed were not available for data after 2014. Before 2014, the surveyed months were not available for half of the sites. From the information we could obtain, the seasonal distribution of fatality searches during the year was very similar to the distribution of our acoustic samplings (see figure A1 in suppl. Material). The spatial distribution of the mortality survey sites was very similar to the one of wind masts (see figure A2 in suppl. material), except for Northern and Eastern France, where we had more wind masts. Fatality data were collected from 2008 to 2012. From the information available, the zone swept by the rotor blades 
was then above $32(+/-8)$ meters high. We defined species susceptibility to collisions as the mortality rate relative to species density. To calculate this latter value, we used acoustic data and accounted for variations in acoustic detectability between species. For each species, for the whole French territory, the density index was calculated as follows:

eqn 1 Density index $=\frac{\text { Mean activity }}{\text { Detection distance }}$,

where detection distance is the approximate maximal distance from which an individual of a species can be acoustically detected (Barataud, 2015) and where mean activity was taken from the French reference scale of activity levels "Actichiro" (Haquart, 2013). The latter was built from acoustic recordings on more than 2,757 nights between 2007 and 2011 and orders species on a scale from the least to the most commonly recorded. This reference scale used recordings from microphones installed at ground level only. However, in our dataset, species relative activity recorded from ground is similar to species relative total activity (sum of ground level and height activity) (Pearson's $r=0.98$; see table A1 in suppl. material). The recordings in Actichiro oversampled the Mediterranean region (see table A2 in supplementary material) while our sampling was more balanced (see table A5 in supplementary material). Thus, we used a mean activity weighted by the areas of the four biogeographical regions to get more accurate measures of species relative density all over the country. To do this, we multiplied the mean activities for each of the four biogeographical regions by a regional area ratio (i.e. region area divided by the area of the whole French territory). We then summed all weighted mean activities to obtain a French mean activity. Since no activity data was available for Belgium, our collision susceptibility index relied only on data from France. It was calculated as follows for each species:

eqn 2 Collision susceptibility index $=\frac{\text { Number of carcasses }+1}{\text { Density index }}$, 
where number of carcasses is the total amount of bat carcasses found at French wind farms. We added one to the number of carcasses for each species to avoid a multiplication by zero. The limit of this method lies in the overcorrection of the susceptibility of rare species.

Correlation between the ratio of time spent at height and collision susceptibility index

We used a generalised linear mixed model (GLMM) to estimate rates of flight at height for each species. Bat pass height was modelled as a binomial variable (at height or at ground level) according to species as a fixed effect. In order to take into account the local environment effect on flight behaviour, study sites were introduced as a random variable. The GLMM was built using the glmmPQL function of the MASS package (Venable and Ripley, 2002) of R (R Core Team, 2014). The estimated species rate of flight at height was then correlated to species collision susceptibility index. The first variable did not follow a normal distribution and for this reason a Spearman's rank correlation test was performed. The same method has been applied to test the correlation between the total amount of bat passes at height and the raw fatality counts.

\section{Results}

Flight heights of 340,797 bat passes have been recorded, among which 330,740 could be attributed to a species or a group of species and used for further analysis. At least 28 species have been determined. The most commonly recorded species was $P$. pipistrellus. On average, $10 \%$ of its time was spent at height (Table A3: Ratio of time spent at height for each species.Figure 4). The small Myotis group contains data from at least M. alcathoe, M. bechsteinii, M. brandtii, M. capaccinii, M. emarginatus, $M$. nattereri, M. daubentonii, M. dasycneme and M. mystacinus (see table A4 in suppl. material for details). The only bat passes at height that could be identified for this group were from $M$. daubentonii and for a probable $M$. dasycneme. The Plecotus group contains data from at least $P$. auritus and $P$. austriacus and both have been recorded at height. Rhinolophus bats are the only genus that was never recorded at height. All Nyctalus bats, Tadarida teniotis and Vespertilio murinus spent more than $40 \%$ of their time at height. 
The collision susceptibility index, which takes into account the abundance of species, classified $V$. murinus, Nyctalus bats and P. nathusii as most susceptible to WT collisions (Erreur ! Source du renvoi introuvable.). P. pipistrellus had a low level of susceptibility to collisions (Erreur ! Source du renvoi introuvable.) despite being the most common species found in mortality surveys (Rodrigues et al., 2015). Small Myotis, Plecotus, Barbastella and Rhinolophus had a very low level of susceptibility (Erreur ! Source du renvoi introuvable.).

A significant correlation (rho $=0.94 ; \mathrm{p}=4.57 \mathrm{e}-06$ ) could be demonstrated between species' susceptibility to WT collisions and their preference to fly at height (Figure 5). Low flying species

257

258 (Rhinolophus, small Myotis and Plecotus bats) correspond to species with a low index and high flying species (Nyctalus, Vespertilio and Tadarida bats) to a high index. A significant correlation has also been found between the total amount of bat passes at height and the raw fatality counts (see figure A3 in suppl. material).

There was a high correlation between the number of bat passes recorded from the ground microphone and the number of bat passes recorded from the upper microphone for certain species (e.g. N. noctula and N. leisleri), however the activity at height of several species (e.g. Small Myotis or P. pipistrellus) could not be explained by the ground microphone only, or poorly (see Table A1 in suppl. Material).

\section{Discussion}

\section{Flight behaviour}

The dataset presented here is the first objective assessment of flight height distribution of European species, at similar environments to where wind blades operate. It extends the results found by Müller et al. (2013) by covering several landscape types with a very large sample size, ensuring a fair representativeness of the variability that may occur across several biogeographical regions.

Our results show that species flight behaviour can be organised into three different categories embracing Denzinger and Schnitzler (2013) guilds definitions. The first category includes four 
different guilds, namely edge space trawling foragers and narrow space active gleaning foragers (i.e. small Myotis), narrow space flutter detecting foragers (i.e. Rhinolophus) and narrow space passive gleaning foragers (i.e. Plecotus, Barbastella and large Myotis). These species were always or almost exclusively located at ground level. The second category corresponds to the guild of edge space aerial foragers with species flying more often close to the ground or vegetation than at height (i.e. Miniopterus, Pipistrellus, Eptesicus and Hypsugo species). The third category corresponds to the guild of open space aerial foragers (i.e. Nyctalus, Tadarida and Vespertilio species), that spent a considerable proportion of time at high heights. These results underline the close relationship between bat sonar and flight behaviour. Indeed, the first group mainly uses very high-pitched frequencies and/or strongly modulated frequencies, with short duration (Rhinolophus excluded because of their use of a specific strategy to detect prey flutter (Schnitzler and Denzinger, 2011)), implying a short acoustical range. The third group on the other hand often uses quasi-constant frequencies with very short bandwidth and long duration calls, which carries a signal over long distances (Barataud, 2015). The first acoustical strategy is adequate to forage and commute close to the ground and vegetation whereas the second is on the contrary best suited for high flight. Between those two groups, one can clearly observe a progressive range of those acoustical strategies (e.g. Eptesicus serotinus, which displays low frequencies but large bandwidths). The specific distribution of flight heights found in our study is concordant with what is described in the literature (Arthur and Lemaire, 2015; Dietz et al., 2009; Rodrigues et al., 2015).

\section{Correlation between fatalities and behaviour}

In order to establish a relationship between species distinctive flight height distribution and their susceptibility to WT collisions, a proper method for the assessment of this susceptibility had to be chosen. Since study sites with standardised methods in both pre-construction acoustic surveys and post-activation fatality surveys are very scarce, we chose to use publicly available mortality data from French wind farms. Here, to distinguish between the effect of behaviour and density, French carcass counts had to be corrected for species abundance. Relative densities for bat species are only available 
in the literature for the French territory (Haquart, 2013). This approach is worth considering for other territories and opens novel possibilities for assessing correlations such as the one presented here.

Our results demonstrate that species susceptibility to WT collision is highly correlated with their propensity to spend time at height (i.e. at collision risk) when monitored from wind masts. This novel finding disentangles the roles played by species densities on one hand, and by species flight height on the other hand, and brings new elements to the understanding of the ultimate causes of WT collisions (see Cryan and Barclay, 2009). Furthermore, the behavioural relevance of this relationship is that tall structures like wind masts or WT seem to act as similar auditory or visual stimuli to bats, as this was suggested by Jameson and Willis (2014) for North American species.

\section{Limits and proposals for improvement}

The robustness of the correlation has to be enhanced with more observations for rare species. $T$. teniotis and $N$. lasiopterus populations for instance are suspected to be significantly impacted by WT, although few data have been reported in France -1 and 6 carcasses respectively (Rodrigues et al., 2015). Spain and Portugal studies report the majority of mortality data for these two large European species. According to French population densities calculated by Haquart (2013), they are among the five rarest species in the French Mediterranean region $\left(57000 \mathrm{~km}^{2}\right)$. The estimates are of about 16000 individuals for T. teniotis and about 600 individuals for $N$. lasiopterus. The impact of WT might be underestimated because of the low probability to find the carcasses of rare species.

The results presented here were obtained from data originating from relatively small WT (rotor blades above $32(+/-8)$ meters high) or wind masts compared to many WT that are currently being built. However, we can assume that flight height distribution of each species are simple gradients, thus species ordering along the susceptibility gradient should not change according to WT height.

Bat fatalities at wind farms collected by EUROBATS are not corrected for predation rates, the efficiency of the observer and the surface prospected. It is one of the reasons why the correlation 
established in our study is a relative correlation and cannot be used as such to predict the number of carcasses that would be found at a WT by an acoustic survey alone. To achieve this goal, a different method has to be used, where flight height monitoring and carcass searches would be performed at the same sites. Korner-Nievergelt et al. (2013) achieved this work in Germany with the formulation of an N-mixture model from acoustic surveys at WT nacelles. This allowed the prediction of bat fatalities from acoustic monitoring data at the WT nacelle. The same undertaking has to be done before and after the wind farm installation in order to predict bat fatalities from pre-construction acoustic surveys. This has been attempted by Hein et al. (2013) but the relationship between both variables was not conclusive. It will be greatly improved if the data collection methods are standardised and if precision in bat species identification is enhanced.

\section{Applications of the collision susceptibility index}

Finally, the creation of an index for species susceptibility to WT collisions, independently of their abundance, is an important achievement for the objectivity of impact assessment studies. The latter need this index in order to assess a local susceptibility to collisions, using additional information such as local activity level recorded from the ground and site function (e.g. presence of roost, presence of foraging activity). Unless bat flight height distribution is significantly different from one geographical region to another - which remains to be studied - this index could potentially be used in studies from any European region where those species are extant. But this index neglects possible variations in flight behaviour across locations, that can be assessed with recordings from wind masts. Our results indeed support that studying bat acoustic activity on a wind mast is a powerful method to assess impacts prior to the settlement of wind farms.

\section{Variability of flight height}

Abiotic and biotic factors, such as wind speed, insect concentrations, or vegetation height are known to influence bats flying heights (e.g. Menzel et al., 2005; Arthur and Lemaire, 2015; Kunz et al., 2007, Rydell et al., 2010). In addition, knowledge about the precise distribution of migration flight routes is missing in the literature. The position of a study site on one of these routes might significantly alter 
flight heights. While the response of bats to meteorological factors that fluctuate year-round at one study site are easily monitored, very little information exists about the precise influence operated by habitat variables on bat flight altitude. Some studies explored the link between, on one hand, bat mortality and activity, and on the other hand, bat mortality and habitat (e.g. Ferreira et al., 2015, Johnson et al., 2004, Arnett et al., 2016). However, the question of how habitat alters flight height was to our knowledge only addressed by Menzel et al. (2005) on five bat species with one sampling per habitat. Throughout Europe, a multitude of small datasets with similar methodologies are collected each year for the purpose of WT impact assessment studies. Put together, they would offer an excellent opportunity to study this relationship more thoroughly.

\section{Acknowledgments}

The present work was a collaboration between Biotope and the Muséum national d'Histoire naturelle in the form of a PhD thesis funded by Biotope and the Association Nationale de la Recherche et de la Technologie. We would like to thank EUROBATS and all the contributors for providing mortality data and Alexandre Haquart for his remarkable work developing Actichiro, and for advising us for this study. We would also like to thank Sébastien Devos, Marie-Lilith Patou, Julien Mérot, Alexandre Haquart, Julien Tranchard, Philippe Ferragne, Matthieu Guyot, Antonin Dhellemme and Julien Renglet for their important contributions to equipment design and installation, data collection and acoustic analysis.

\section{Conflict of interest}

Biotope is an environmental consultancy involved in wind turbine impact assessment studies. Two of the authors, Charlotte Roemer and Thierry Disca, were employees at Biotope at the time of submission. Yves Bas was an employee at Biotope until March 2014. Authors thus declare a direct conflict of interest according to Elsevier ethics. However, all data used to calculate bat susceptibility to wind turbines were taken from the literature and are completely independent from Biotope's activities and clients. Authors furthermore take complete responsibility for the integrity of the data related to flight behaviour and the accuracy of their analysis. 


\section{References}

389

390

391

392

393

394

395

396

397

398

399

400

401

402

403

404

405

406

407

408

409

410

411

412

413

414

415

416

417

418

419

420

421

422

Arnett, E. B., Baerwald, E. F., Mathews, F., Rodrigues, L., Rodríguez-Durán, A., Rydell, J., VillegasPatraca R. \& Voigt, C. C. (2016). Impacts of wind energy development on bats: a global perspective. In Bats in the Anthropocene: Conservation of Bats in a Changing World (pp. 295-323). Springer International Publishing.

Arthur, L., \& Lemaire, M. (2015). Les Chauves-souris de France, Belgique, Luxembourg et Suisse. $2^{\text {nd }}$ ed. Biotope.

Barataud, M. (2015). Acoustic Ecology of European Bats. Species Identification, Study of Their Habitats and Foraging Behaviour. Biotope, Mèze/Muséum national d'Histoire naturelle, Paris.

Collins, J. \& Jones, G. (2009) Differences in Bat Activity in Relation to Bat Detector Height: Implications for Bat Surveys at Proposed Windfarm Sites. Acta Chiropterologica, 11, 343-350.

Council Directive 92/43/EEC 1992. Conservation of natural habitats and of wild flora and fauna. International Journal of the European Communities, L206: 7-49.

Cryan, P.M. \& Barclay, R.M.R. (2009) Causes of bat fatalities at wind turbines: hypotheses and predictions. Journal of Mammalogy, 90, 1330-1340.

Cryan, P. M., Gorresen, P. M., Hein, C. D., Schirmacher, M. R., Diehl, R. H., Huso, M. M., Hayman, D. T. S., Fricker, P. D., Bonaccorso, F. J., Johnson, D. H., Heist, K. and Dalton, D.C. (2014). Behavior of bats at wind turbines. Proceedings of the National Academy of Sciences, 111(42), 15126-15131.

Denzinger, A \& Schnitzler, H.U. (2013) Bat guilds, a concept to classify the highly diverse foraging and echolocation behaviors of microchiropteran bats. Frontiers in Physiology, 4, 164.

Dietz, C., von Helversen, O., \& Nill, D. (2009). Bats of Britain, Europe and Northwest Africa (p. 400).

Ferreira, D., Freixo, C., Cabral, J. A., Santos, R. \& Santos, M. (2015) Do habitat characteristics determine mortality risk for bats at wind farms? Modelling susceptible species activity patterns and anticipating possible mortality events. Ecological Informatics, 28, 7-18.

Frick, W. F., Baerwald, E. F., Pollock, J. F., Barclay, R. M. R., Szymanski, J. A., Weller, T. J., Russel, A.L., Loeb S.C., Medellin R.A. \& McGuire, L. P. (2017). Fatalities at wind turbines may threaten population viability of a migratory bat. Biological Conservation, 209, 172-177.

Georgiakakis, P., Kret, E., Cárcamo, B., Doutau, B., Kafkaletou-Diez, A., Vasilakis, D. \& Papadatou, E. (2012) Bat Fatalities at Wind Farms in North-Eastern Greece. Acta Chiropterologica, 14, 459-468.

Hammerson, G. A., Kling, M., Harkness, M., Ormes, M., \& Young, B. E. (2017). Strong geographic and temporal patterns in conservation status of North American bats. Biological Conservation, 212, $144-152$.

Haquart, A. (2013) Actichiro. Référentiel d'activité des chiroptères : éléments pour l'interprétation des dénombrements de chiroptères avec les méthodes acoustiques en zone méditerranéenne française. Mémoire de l'EPHE, septembre 2013. 
Harrell, F. E. with contributions from Charles Dupont and many others (2014) Hmisc: Harrell Miscellaneous. R package version 3.14-6. http://CRAN.R-project.org/package=Hmisc

Hein, C. D., Gruver, J. \& Arnett, E. B. (2013) Relating pre-construction bat activity and postconstruction bat fatality to predict risk at wind energy facilities: a synthesis. A report submitted to the National Renewable Energy Laboratory. Bat Conservation International, Austin, TX, USA.

Holderied, M.W. \& von Helversen, O. (2003) Echolocation range and wingbeat period match in aerialhawking bats. Proc Biol Sci, 270, 2293-2299.

Holderied, M. W., \& Jones, G. (2009) Flight dynamics. In : Ecological and behavioral methods for the study of bats. Johns Hopkins University Press, Baltimore, MD, USA, 459-475.

Jameson, J. W. \& Willis, C. K. (2014) Activity of tree bats at anthropogenic tall structures: Implications for mortality of bats at wind turbines. Animal Behaviour, 97, 145-152.

Jensen, M.E. \& Miller, L.A. (1999) Echolocation signals of the bat Eptesicus serotinus recorded using a vertical microphone array: effect of flight altitude on searching signals. Behavioural Ecology and Sociobiology, 47, 60-69.

Johnson, G. D., Perlik, M. K., Erickson, W. P. \& Strickland, M. D. (2004) Bat activity, composition, and collision mortality at a large wind plant in Minnesota. Wildlife Society Bulletin, 32(4), 12781288.

Korner-Nievergelt, F., Brinkmann, R., Niermann, I. \& Behr, O. (2013) Estimating bat and bird mortality occurring at wind energy turbines from covariates and carcass searches using mixture models. PLoS ONE 8(7):e67997.

Kunz, T.H., Arnett, E.B., Erickson, W.P., Hoar, A.R., Johnson, G.D., Larkin, R.P., Strickland, M.D., Thresher, R.W. \& Tuttle, M. (2007) Ecological impacts of wind energy development on bats: questions, research needs, and hypotheses. The Ecological Society of America.

Leung, D. Y. \& Yang, Y. (2012). Wind energy development and its environmental impact: a review. Renewable and Sustainable Energy Reviews, 16(1), 1031-1039.

Menzel, J. M., Menzel, M. A., Kilgo, J. C., Ford, W. M., Edwards, J. W. \& McCracken, G. F. (2005) Effect of habitat and foraging height on bat activity in the coastal plain of South Carolina. Journal of Wildlife Management, 69(1), 235-245.

Müller, J., Brandl, R., Buchner, J., Pretzsch, H., Seifert, S., Strätz, C., Veith, M. \& Fenton, B. (2013) From ground to above canopy ? Bat activity in mature forests is driven by vegetation density and height. Forest Ecology and Management 306, 179-84.

Newson, S. E., Evans, H. E. \& Gillings, S. (2015) A novel citizen science approach for large-scale standardised monitoring of bat activity and distribution, evaluated in eastern England. Biological Conservation, 191, 38-49.

Rodrigues, L., Bach, L., Duborg-Savage, M. J., Karapandza, B., Kovac, D., Kervyin, T., Dekker, J., Kepel, A., Bach, P., Collins, J., Harbusch, C., Park, K., Micevski, B. \& Minderman, J. (2015). Guidelines for consideration of bats in wind farm projects-Revision 2014. EUROBATS Publication Series, (3). 

mortality at wind turbines in northwestern Europe. Acta Chiropterologica, 12(2), 261-274. Mortality of bats at wind turbines links to nocturnal insect migration? European Journal of Wildlife Research, 56, 823-827.

Rydell, J., Bogdanowicz, W., Boonman, A., Pettersson, S., Suchecka, E. \& Pomorski, J. J. (2016). Bats may eat diurnal flies that rest on wind turbines. Mammalian Biology-Zeitschrift für Säugetierkunde, 81(3), 331-339.

R Development Core Team (2008) R: A language and environment for statistical computing. R Foundation for Statistical Computing, Vienna, Austria. ISBN 3-900051-07-0, URL http://www.Rproject.org.

Schnitzler, H. U. \& Denzinger, A. (2011). Auditory fovea and Doppler shift compensation: adaptations for flutter detection in echolocating bats using CF-FM signals. Journal of Comparative Physiology A, 197(5), 541-559.

Voigt, C. C., Lehnert, L. S., Petersons, G., Adorf, F. \& Bach, L. (2015) Wildlife and renewable

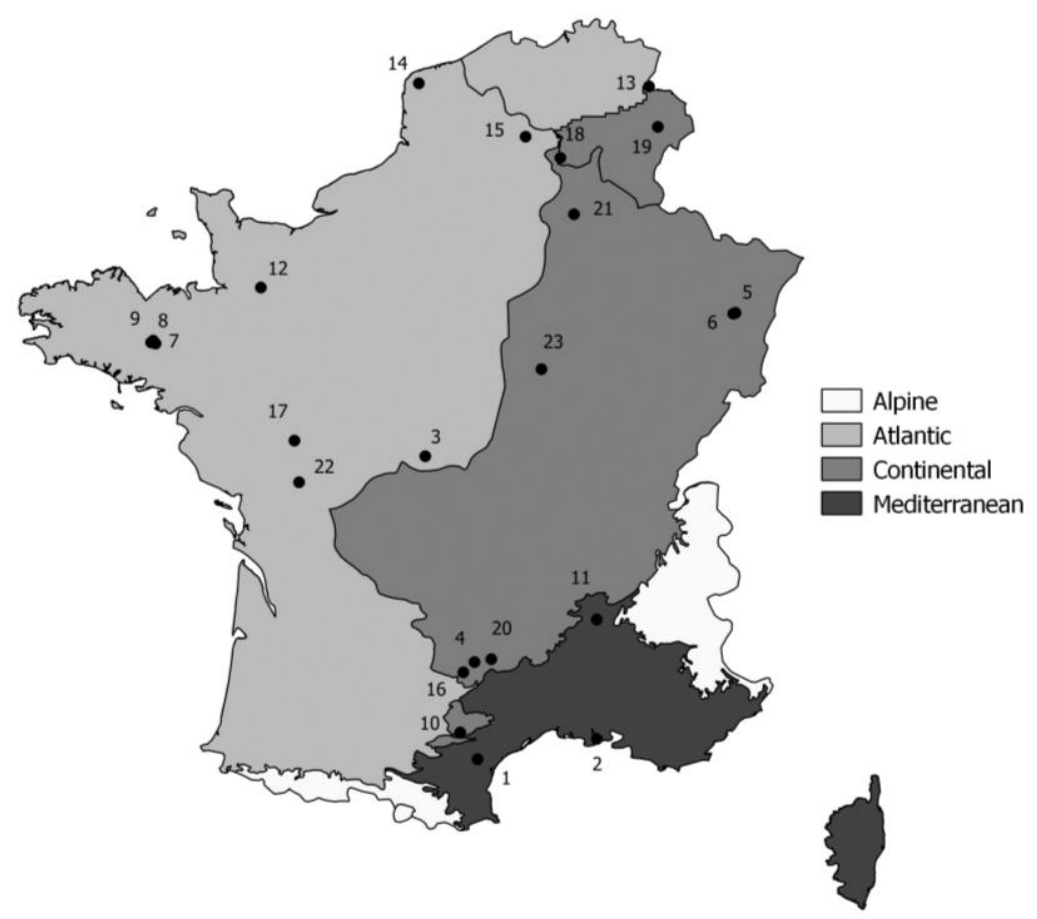

Figure 1: Study sites locations in France and Belgium and the different biogeographical areas. 


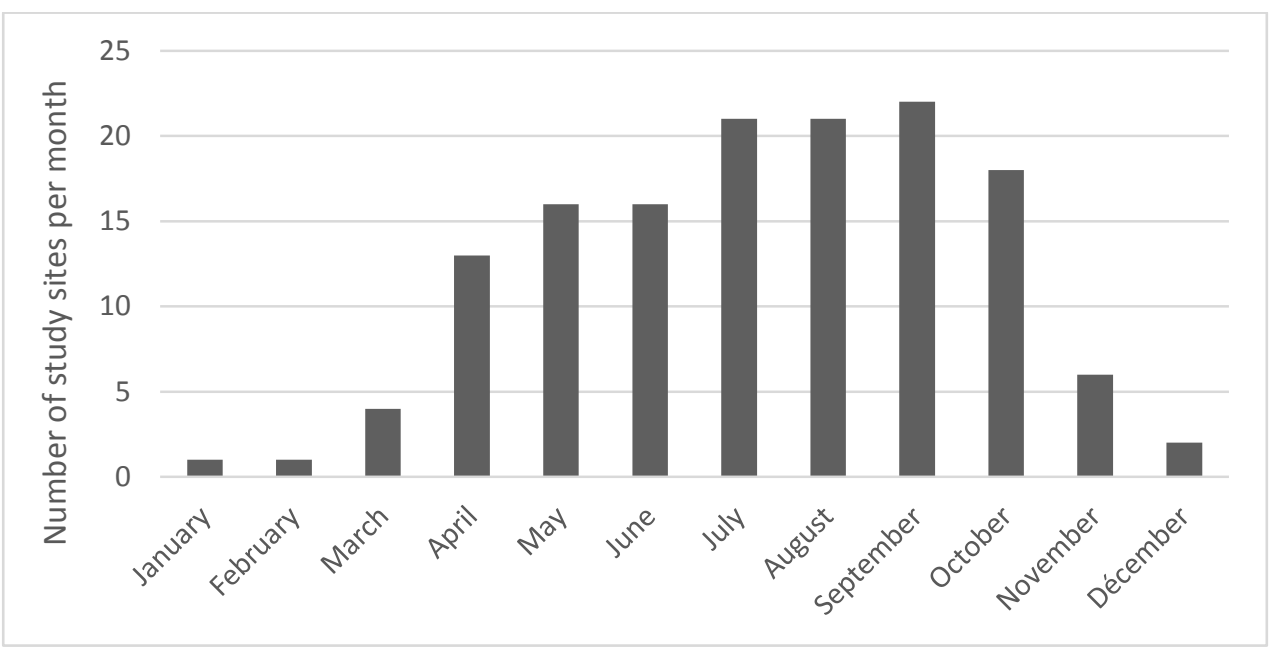

Figure 2: Cumulative number of sites surveyed per month for the six study years.

482

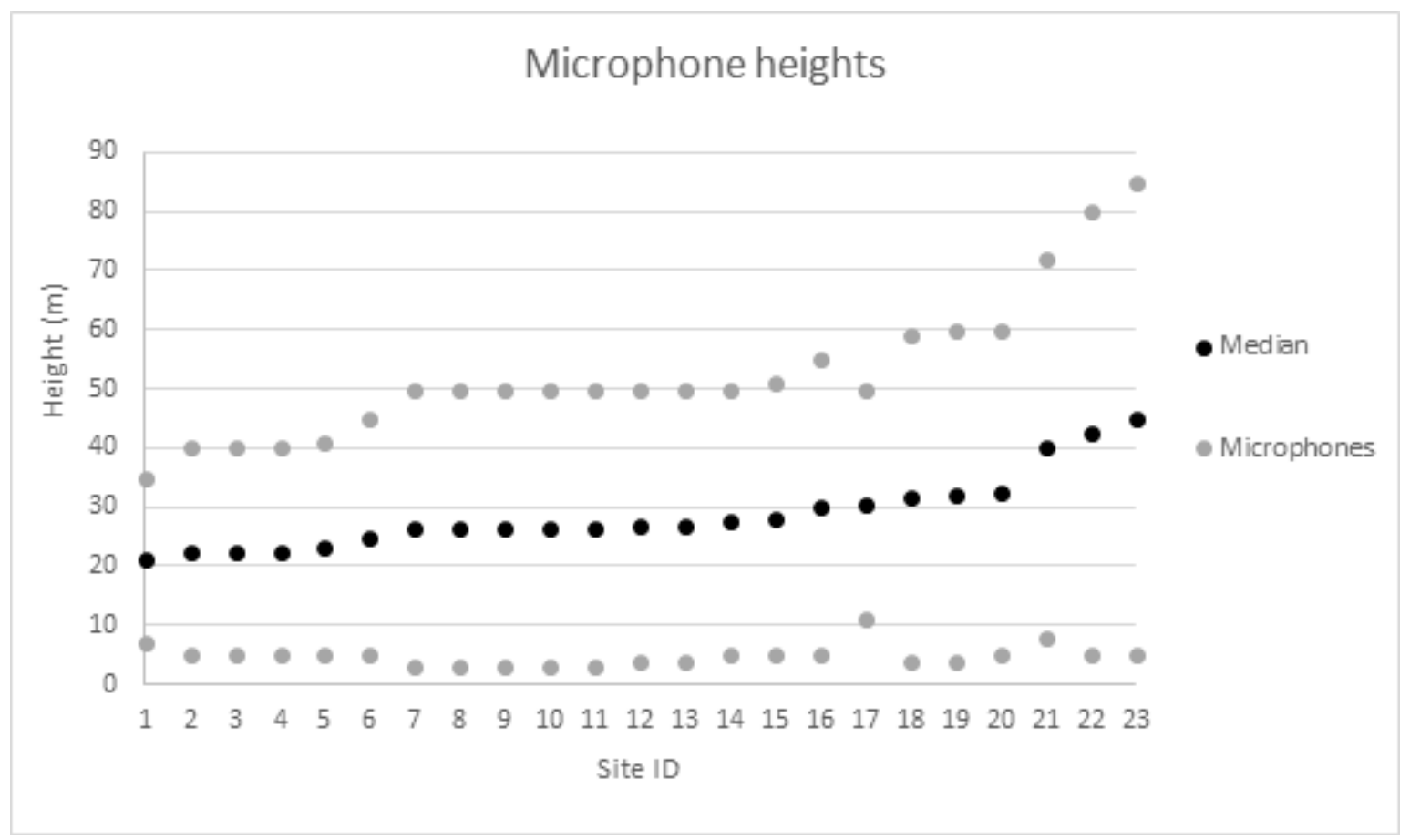

Figure 3: Microphone height and median height for all 23 study sites. 


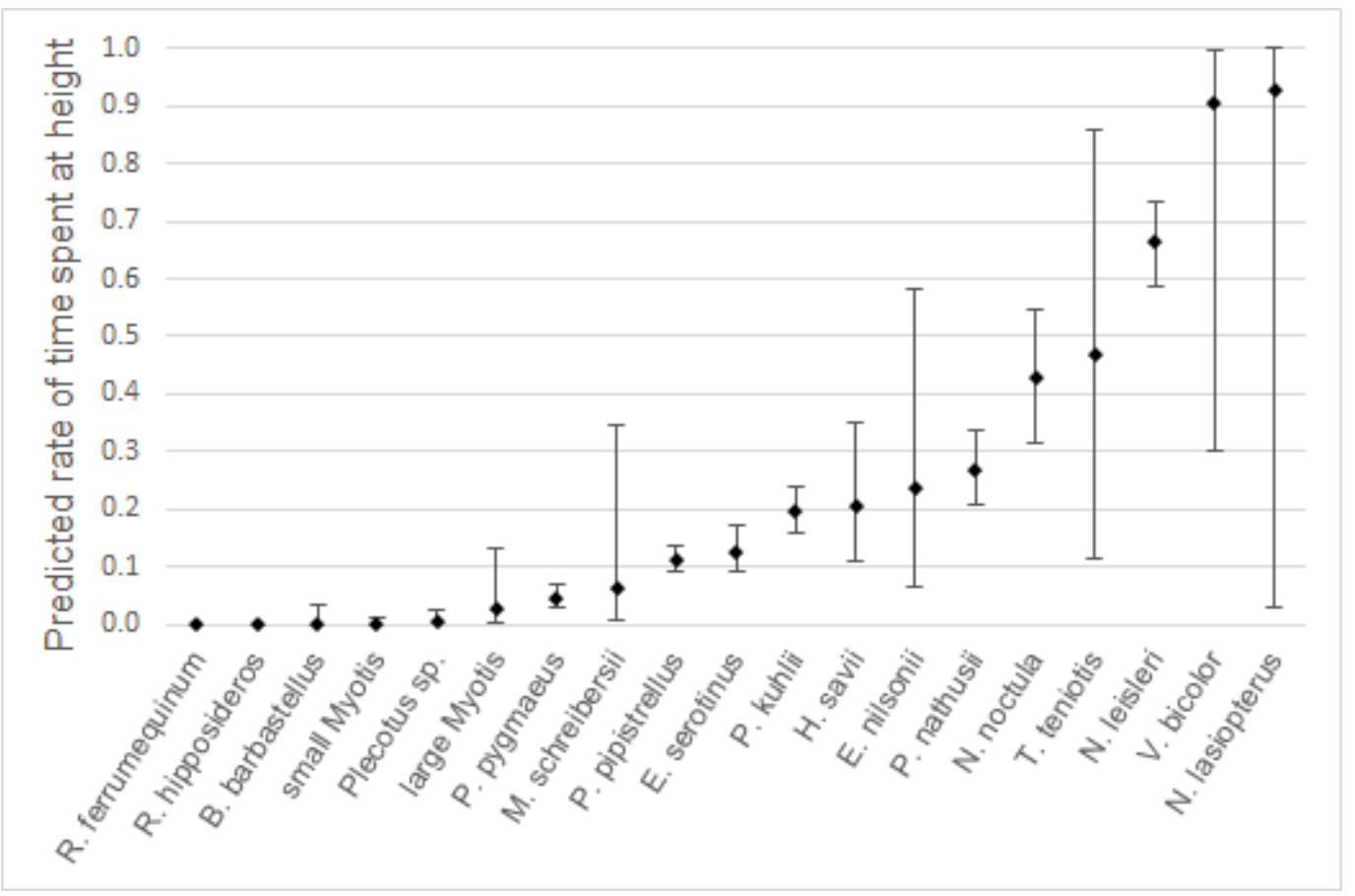

Figure 4 : Ratio of time spent at height for each species. Predicted rates are calculated from the GLMM output and are available in more details in Table A3 in the supplementary material.

Table 1 : Values taken from the literature to calculate a collision susceptibility index to WT. Mean activity at ground and at height microphones correspond to the values of our study sites which contain continuous recordings overnight (i.e. after 2013), for comparison with Actichiro.

\begin{tabular}{|c|c|c|c|c|c|c|}
\hline Species & $\begin{array}{l}\text { Mean } \\
\text { activity } \\
\text { (Positive } \\
\text { minutes } \\
\text { of } \\
\text { activity } \\
\text { /night) } \\
\text { (Haquart } \\
\text {, 2013) }\end{array}$ & $\begin{array}{l}\text { Detection } \\
\text { distance } \\
(\mathrm{m}) \\
\text { (Barataud, } \\
\text { 2015) }\end{array}$ & $\begin{array}{l}\text { Number of } \\
\text { carcasses } \\
\text { FR } \\
\text { (EUROBATS } \\
\text {, 2015) }\end{array}$ & $\begin{array}{l}\text { Collision } \\
\text { susceptibilit } \\
y \text { index }\end{array}$ & $\begin{array}{l}\text { Mean } \\
\text { activity } \\
\text { at } \\
\text { groun } \\
d\end{array}$ & $\begin{array}{l}\text { Mean } \\
\text { activit } \\
y \text { at } \\
\text { height }\end{array}$ \\
\hline small Myotis & 19.59 & 15 & 3 & 3 & 2.32 & 0.02 \\
\hline R. hipposideros & 0.66 & 5 & 0 & 8 & 0 & 0 \\
\hline Plecotus sp. & 1.52 & 23 & 0 & 14 & 0.8 & 0.01 \\
\hline $\begin{array}{r}R . \\
\text { ferrumequinum }\end{array}$ & 0.52 & 10 & 0 & 19 & 0.04 & 0 \\
\hline B. barbastellus & 3.21 & 15 & 3 & 19 & 0.35 & 0 \\
\hline M. schreibersii & 1.44 & 30 & 5 & 125 & 0.11 & 0.02 \\
\hline large Myotis & 0.49 & 20 & 4 & 204 & 0.11 & 0.01 \\
\hline P. pipistrellus & 79.85 & 35 & 622 & 273 & 27.08 & 5.86 \\
\hline E. serotinus & 3.34 & 40 & 23 & 287 & 1.28 & 0.36 \\
\hline P. kuhlii & 9.55 & 30 & 130 & 411 & 3.48 & 1.97 \\
\hline P. pygmaeus & 5.93 & 25 & 125 & 532 & 2.61 & 0.33 \\
\hline T. teniotis & 0.18 & 150 & 1 & 815 & 0.02 & 0.01 \\
\hline H. savii & 1.78 & 40 & 36 & 833 & 0.2 & 0.11 \\
\hline P. nathusii & 3.15 & 35 & 178 & 1991 & 1.36 & 0.89 \\
\hline
\end{tabular}




\begin{tabular}{r|rrrrrr} 
E. nilsonii & 0.02 & 50 & 0 & 2500 & 0 & 0 \\
N. noctula & 1.15 & 100 & 31 & 2783 & 0.07 & 0.14 \\
N. leisleri & 0.87 & 70 & 63 & 5155 & 0.6 & 0.7 \\
N. lasiopterus & 0.08 & 150 & 6 & 12755 & 0 & 0.02 \\
V. murinus & 0.01 & 50 & 8 & 81678 & 0 & 0.01
\end{tabular}

485

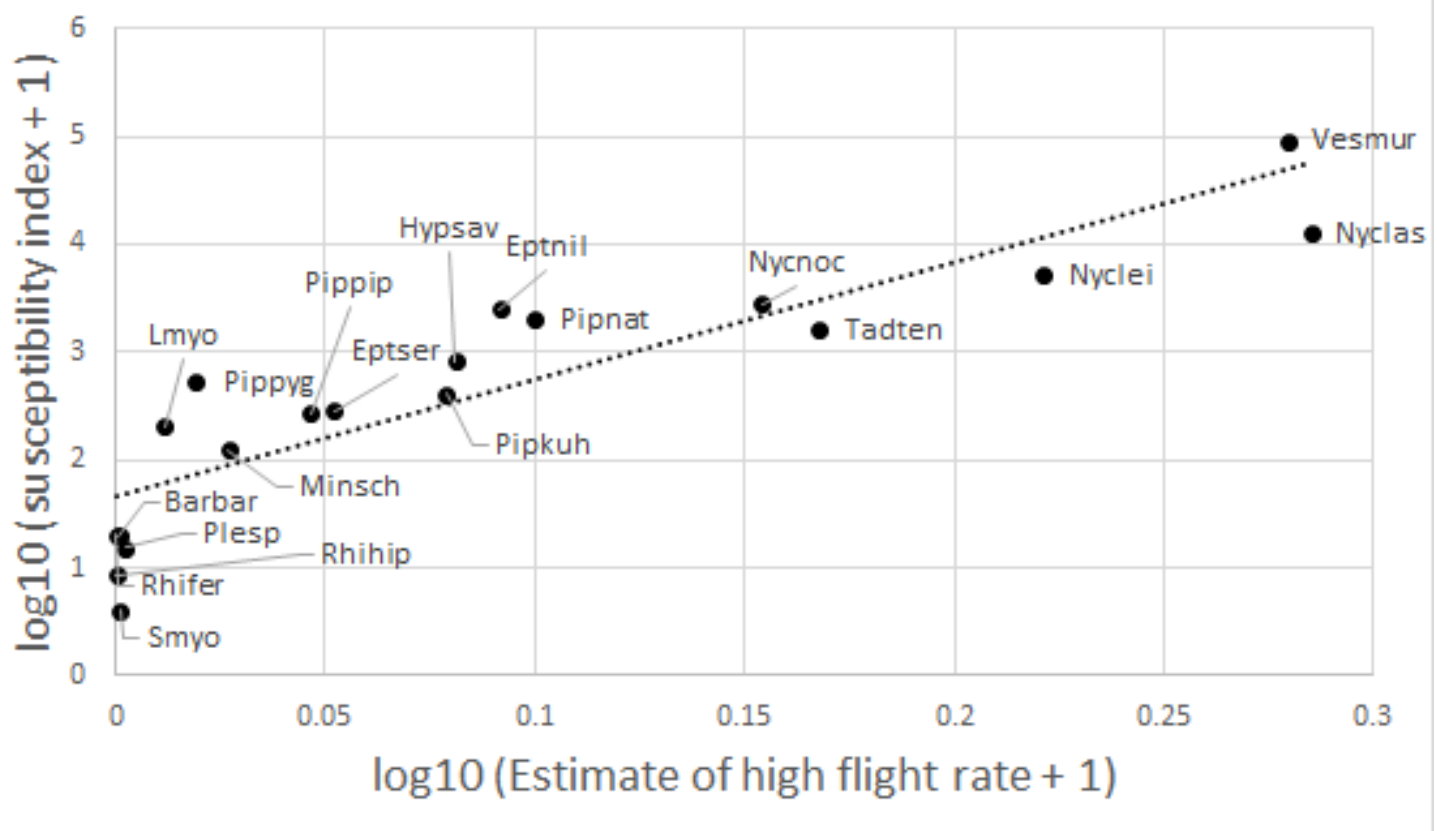

Figure 5: Ratio of time spent at height in function to susceptibility to WT collision. Spearman correlation coefficient rho $=0.94 ; p=4.58 \mathrm{e}-06$. Species names are the three first letters of the genus and of the species name excepted for small Myotis (Smyo) and large Myotis (Lmyo). 


\section{Supplementary material}

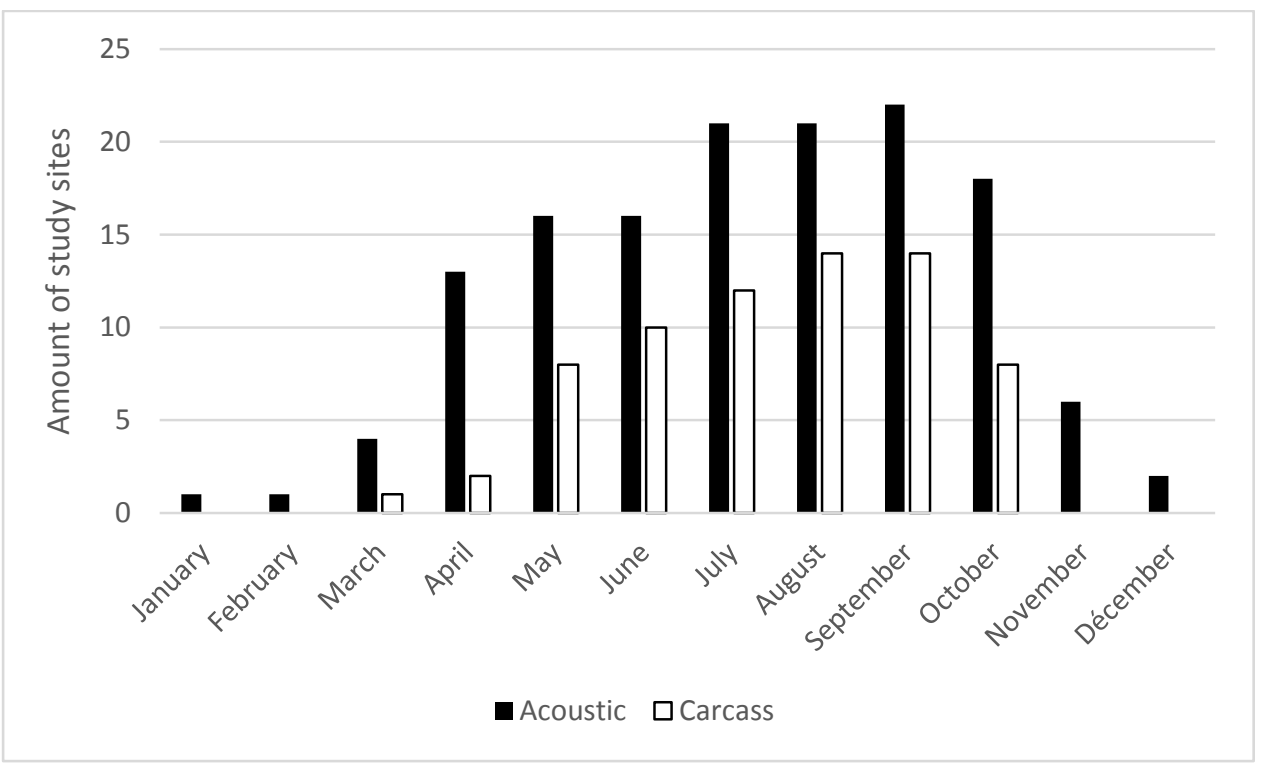

Figure A1: Annual distribution of the acoustic surveys at wind masts used for flight height assessment (black) and of the carcass searches at wind farms (white) (when data was available).

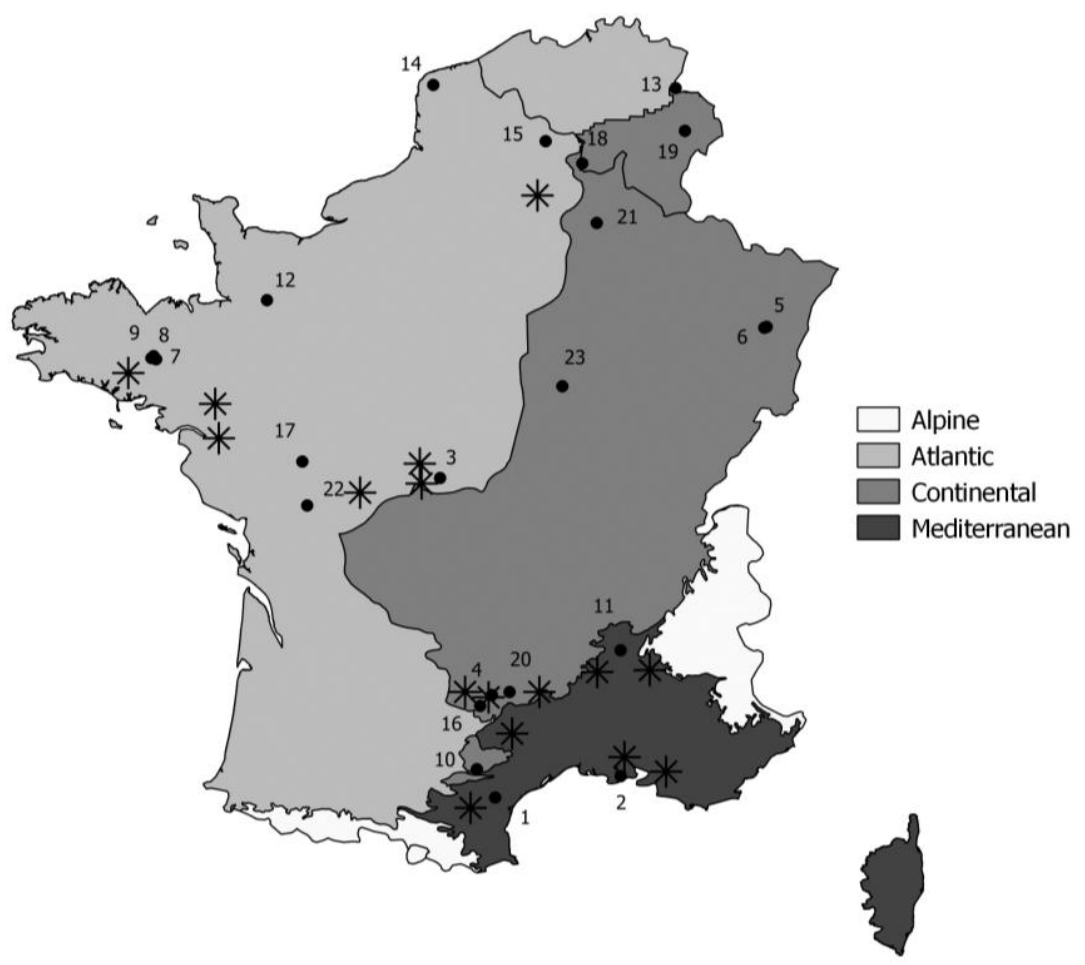

Figure A2: Spatial distribution of the wind masts used for flight height assessment (dots) and of the wind farms where carcass searches were performed (stars) (when data was available). The different biogeographical areas are showed for France and Belgium.

Table A1: Comparison of activity (number of bat passes) recorded from both microphones. Species names are the three first letters of the genus and of the species name excepted for small Myotis (Smyo) and large Myotis (Lmyo). $\mathrm{R}^{2}$ is the correlation between the activity recorded at the ground 
microphone and the activity recorded at the upper microphone where each study site in an observation. NA stands for species that were not observed at height (i.e. Rhinolophus) and for species that were not recorded at more than 15 study sites.

\begin{tabular}{|c|c|c|c|c|c|c|c|}
\hline Source & \multicolumn{2}{|c|}{$<$ median height } & \multicolumn{2}{|c|}{ > median height } & \multirow[t]{2}{*}{ Total } & \multirow{2}{*}{$\begin{array}{l}\text { Percentage } \\
\text { of bat } \\
\text { passes } \\
\text { recorded } \\
\text { from ground } \\
\text { mic }\end{array}$} & \multirow[b]{2}{*}{$\begin{array}{l}R^{2} \\
\text { between } \\
\text { ground } \\
\text { and } \\
\text { height } \\
\text { mic }\end{array}$} \\
\hline Species & $\begin{array}{l}\text { Ground } \\
\text { mic }\end{array}$ & $\begin{array}{l}\text { Ground and } \\
\text { height mic }\end{array}$ & $\begin{array}{l}\text { Ground and } \\
\text { height mic }\end{array}$ & $\begin{array}{l}\text { Height } \\
\text { mic }\end{array}$ & & & \\
\hline Barbar & 4,600 & 55 & 1 & 6 & 4,662 & 99.87 & 0.14 \\
\hline Eptnil & 123 & 6 & 5 & 33 & 167 & 80.24 & NA \\
\hline Eptser & 7,631 & 696 & 219 & 768 & 9,314 & 91.75 & 0.39 \\
\hline Hypsav & 666 & 56 & 24 & 135 & 881 & 84.68 & NA \\
\hline Minsch & 192 & 4 & 9 & 9 & 214 & 95.79 & NA \\
\hline L Myotis & 617 & 14 & 3 & 22 & 656 & 96.65 & 0.55 \\
\hline S Myotis & 8,104 & 118 & 3 & 30 & 8,255 & 99.64 & 0.03 \\
\hline Nyclas & 1 & 1 & 3 & 24 & 29 & 17.24 & NA \\
\hline Nyclei & 1,629 & 353 & 626 & 2,684 & 5,292 & 49.28 & 0.85 \\
\hline Nycnoc & 1,298 & 194 & 292 & 445 & 2,229 & 80.04 & 0.80 \\
\hline Pipkuh & 33,454 & 2,779 & 491 & 6,136 & 42,860 & 85.68 & 0.79 \\
\hline Pipnat & 3406 & 135 & 90 & 1,869 & 5,500 & 66.02 & 0.74 \\
\hline Pippip & 207,392 & 5,029 & 1,608 & 22,856 & 236,885 & 90.35 & 0.52 \\
\hline Pippyg & 8,743 & 66 & 59 & 471 & 9,339 & 94.96 & NA \\
\hline Plesp & 4,023 & 44 & 2 & 22 & 4,091 & 99.46 & 0.23 \\
\hline Rhifer & 198 & & & & 198 & 100 & NA \\
\hline Rhihip & 9 & & & & 9 & 100 & NA \\
\hline Tadten & 38 & 5 & 21 & 21 & 85 & 75.29 & NA \\
\hline Vesmur & 4 & 4 & 16 & 50 & 74 & 32.43 & NA \\
\hline
\end{tabular}

Table A2: Data used for estimations of species density. Sampling effort for each of the biogeographical areas in Haquart (2013).

\begin{tabular}{l|lll}
\multicolumn{1}{c}{ Biogeographical area } & $\begin{array}{l}\text { Number of } \\
\text { sampling } \\
\text { sites }\end{array}$ & Area (km2) & $\begin{array}{l}\text { Number of } \\
\text { sampling sites } \\
\text { per 1000 km2 }\end{array}$ \\
\hline Alpine & 28 & 30,658 & 0.91 \\
Atlantic & 768 & 268,155 & 2.86 \\
Continental & 169 & 184,203 & 0.92 \\
Mediterranean (Corsica excluded) & 752 & 56,918 & 13.21
\end{tabular}

Table A3: Ratio of time spent at height for each species. Predicted rates are calculated from the GLMM output. Standard error for Rhinolophus species could not be estimated (NE) 
because of the nonexistence of occurrences at height.

\begin{tabular}{|c|c|c|c|c|}
\hline Species & GLMM value & $\begin{array}{l}\text { Standard } \\
\text { error }\end{array}$ & Predicted rate & $\begin{array}{l}N \text { bat } \\
\text { passes }\end{array}$ \\
\hline R. ferrumequinum & -24.30 & $\mathrm{NE}$ & 0 & 198 \\
\hline R. hipposideros & -22.93 & NE & 0 & 9 \\
\hline B. barbastellus & -6.38 & 3.06 & 0.002 & 4,662 \\
\hline small Myotis & -5.94 & 1.43 & 0.003 & 8,255 \\
\hline Plecotus sp. & -5.29 & 1.67 & 0.005 & 4,091 \\
\hline large Myotis & -3.58 & 1.7 & 0.027 & 656 \\
\hline P. pygmaeus & -3.05 & 0.44 & 0.045 & 9,339 \\
\hline M. schreibersii & -2.68 & 2.04 & 0.064 & 214 \\
\hline P. pipistrellus & -2.06 & 0.23 & 0.113 & 236,885 \\
\hline E. serotinus & -1.93 & 0.36 & 0.127 & 9,314 \\
\hline P. kuhlii & -1.41 & 0.25 & 0.197 & 42,860 \\
\hline H. savii & -1.36 & 0.75 & 0.205 & 881 \\
\hline E. nilsonii & -1.18 & 1.51 & 0.235 & 167 \\
\hline P. nathusii & -1.01 & 0.33 & 0.267 & 5,500 \\
\hline N. noctula & -0.30 & 0.48 & 0.427 & 2,229 \\
\hline T. teniotis & -0.12 & 1.93 & 0.470 & 85 \\
\hline N. leisleri & 0.68 & 0.34 & 0.664 & 5,292 \\
\hline V. bicolor & 2.23 & 3.06 & 0.903 & 74 \\
\hline N. lasiopterus & 2.57 & 6.03 & 0.929 & 29 \\
\hline
\end{tabular}

Table A4: Detailed number of bat passes located at ground or at height for all species, before pooling species into groups for further analysis.

\begin{tabular}{r|rrr} 
Species & Ground & Height & \multicolumn{1}{r}{ Total } \\
\hline B. barbastellus & 4,655 & 7 & 4,662 \\
Chiroptera sp. & 317 & 73 & 390 \\
Eptesicus/Nyctalus/Vespertillio sp. & 1,205 & 1,101 & 2,306 \\
E. nilssonii & 129 & 38 & 167 \\
E. serotinus & 8,327 & 987 & 9,314 \\
H. savii & 722 & 159 & 881 \\
M. schreibersii & 196 & 18 & 214 \\
M. alcathoe & 1 & & 1 \\
M. bechsteinii & 150 & & 150 \\
M. brandtii & 9 & & 9 \\
M. capaccinii & 1 & & 1 \\
M. dasycneme & 3 & & 3 \\
M. daubentonii & 236 & 2 & 238 \\
M. emmarginatus & 38 & & 38 \\
Large Myotis & 631 & 25 & 656
\end{tabular}




\begin{tabular}{r|rrr} 
M. mystacinus & 48 & & 48 \\
M. mystacinus/brandtii & 6 & & 6 \\
M. nattereri & 781 & & 781 \\
Small myotis & 6,949 & 30 & 6,979 \\
N. lasiopterus & 2 & 27 & 29 \\
N. leisleri & 1,982 & 3,310 & 5,292 \\
N. noctula & 1,492 & 737 & 2,229 \\
P. kuhlii/nathusii & 6,256 & 1,114 & 7,370 \\
P. kuhlii & 36,233 & 6,627 & 42,860 \\
P. nathusii & 3,541 & 1,959 & 5,500 \\
P. pipistrellus & 212,421 & 24,464 & 236,885 \\
P. pygmaeus & 8,809 & 530 & 9,339 \\
Plecotus sp. & 3,582 & 17 & 3,599 \\
P. auritus & 382 & 3 & 385 \\
P. austriacus & 99 & 1 & 100 \\
R. ferrumequinum & 198 & & 198 \\
R. hipposideros & 9 & & 9 \\
T. teniotis & 43 & 42 & 85 \\
V. murinus & 8 & 66 & 74 \\
Total & 299,461 & 41,336 & 340,797
\end{tabular}

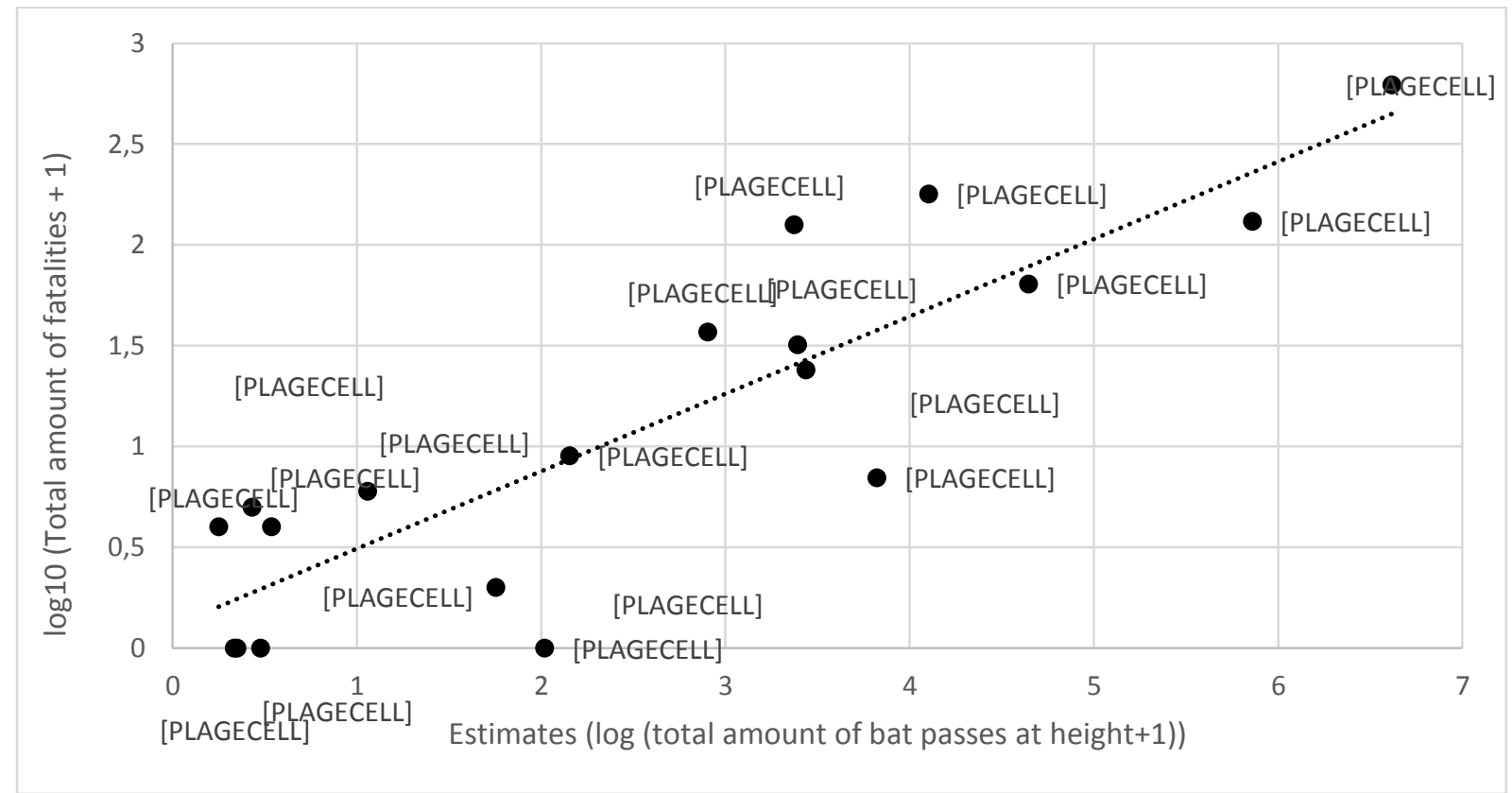

Figure A3: Correlation between the raw count of bat carcasses and the estimated species number of bat passes at height (rho $=0.84)$. We used the same generalised linear mixed model (GLMM) structure as the one described in Material and Methods to estimate the numbers of bat passes at 
height (and respectively at ground) for each species. These estimates were then correlated to species fatality counts.

Table A5: Detail of the proportion of bat passes between microphones at ground and height for the three different biogeographical regions. Species names are the three first letters of the genus and of the species name excepted for small Myotis (Smyo) and large Myotis (Lmyo).

\begin{tabular}{r|rrrrrr} 
Region & \multicolumn{2}{c}{ Atlantic } & \multicolumn{2}{c}{ Continental } & \multicolumn{2}{c}{ Mediterranean } \\
\hline Source & Ground & Height & Ground & Height & Ground & Height \\
localisation & & & & & & \\
Barbar & 4,472 & 5 & 174 & 1 & 9 & 1 \\
Eptnil & & & 129 & 38 & & \\
Eptser & 6,450 & 750 & 469 & 81 & 1,408 & 156 \\
Hypsav & & 2 & 33 & 2 & 689 & 155 \\
Minsch & & & 15 & 1 & 181 & 17 \\
L Myotis & 163 & 8 & 442 & 17 & 26 & \\
S Myotis & 4,927 & 16 & 2,987 & 5 & 308 & 12 \\
Nyclas & & & 2 & 27 & & \\
Nyclei & 1,115 & 1,090 & 511 & 1,746 & 356 & 474 \\
Nycnoc & 1,463 & 683 & 13 & 31 & 16 & 23 \\
Pipkuh & 14,238 & 790 & 4,836 & 189 & 17,159 & 5,648 \\
Pipnat & 1,357 & 771 & 344 & 938 & 1840 & 250 \\
Pippip & 99,881 & 8,789 & 80,993 & 13,119 & 31,547 & 2,556 \\
Pippyg & 69 & 3 & 9 & & 8,731 & 527 \\
Plesp & 3,508 & 17 & 395 & 2 & 164 & 5 \\
Rhifer & 184 & & 2 & & 12 & \\
Rhihip & 5 & & 2 & & 2 & \\
Tadten & & & 6 & 7 & 37 & 35 \\
Vesmur & 3 & 4 & 2 & 59 & 3 & 3
\end{tabular}

